\title{
A CASE STUDY OF AUTOCAD 2D ENGINEERING DRAWING PERFORMANCE AMONG FURNITURE AND PRODUCT DESIGN (BFPD) STUDENTS
}

\author{
Indera Irawan M. R and Affandi H.M \\ Faculty Of Education, The National University of Malaysia
}

\begin{abstract}
Automatic Computer Aided Design (AutoCAD 2D) engineering drawing is an important component in BFPD courses. This software is commonly practiced by students for product design process as part of the project development. However, there is a lack of quality in $2 \mathrm{D}$ engineering drawing that affects the students' prototype making process and project progression. This paper intends to identify the problems that weakened the students' performances of the AutoCAD 2D engineering drawings. Data were collected from the students' examinations, assignments and independent projects. Semi structured interviews were also conducted with the students. The sample consisted of BFPD's Year 2 and Year 3 students at the First City University College. The findings indicated that the lacking of technical skills is the main contribution of this study. Therefore, future research is needed to investigate the identified problems further and recommendations are also made to improve the syllabus.
\end{abstract}

Keywords: AutoCAD, 2D Engineering Drawing, Learning, Product Design

\section{Introduction}

Automatic Computer Aided Design (AutoCAD) is a software application for 2D CAD and 3D CAD drawing model, drafting and engineering drawing. It was founded by Autodesk in 1982 (Kennedy, 2014). AutoCAD can be used to draw, record data such as tolerances, construction materials of prototypes, and analyze drawing without producing the prototypes (Reddy, 2008). AutoCAD software is specifically designed for drafters in specific job-roles and industries (Daniel Greenspan, 2010). According to Guntur Dzulfikar (2014), he claimed that AutoCAD is the world's most commonly used CAD software with the highest overall job-market demand. Therefore, it is widely introduced to students in institutions of higher learning, so they can get the exposure to the software and fulfill the market demand concurrently (Awang, 2000). According to Monk in 1996 noted in his research that all students should have explored and utilized computing as it was used by professionals within their respective field of study, and the upper level courses with significant computing content should be available in each major. In this paper, it focuses on 2D drafting which is useful for various engineering sectors such as electrical design, mechanical design, product design, building design, and architectural rendering and design (Eteli \& Eniekenemi, 2016). Although 3D solid modeling mechanical CAD (3D drafting) on the personal computer (PC) has been available for more than 20 years, the demand for 2D CAD or 2D engineering drawing solutions is still strong, especially for product design and factory management (Seats, 2015). Therefore, the introduction of AutoCAD 2D engineering drawing in the universities and technical schools can meet the need of the industry such as furniture and product design (Serdar, 2015).

\section{Research Background}

Bachelor of Art (Hons) Furniture and Product Design (BFPD) is one of the programmes offered at First City University College (FCUC). The students who are taking this courses are required to learn AutoCAD for their 2D engineering drawing (Nichols, 2013). It is common to adopt a 2D engineering drawing for a product design as part of the project developments . However, the applicability of this software to develop design project 
modules is limited that there is a lacking of quality and knowledge on AutoCAD 2D engineering drawing (2D drafting) in their student's Design Project modules. This insufficiencies influences the prototype making process and overall project progression (Beckmann \& Krause, 2010).

AutoCAD module is one of the courses to help students in preparing their documentation for design project modules. The Design Project Module is a major course studied by the BFPD's students that requires them to understand the whole design process. After the students have completed their $2 \mathrm{D}$ engineering drawing or design documentation, they will enter workshop to build up their own prototype or model making (refer to figure 1).

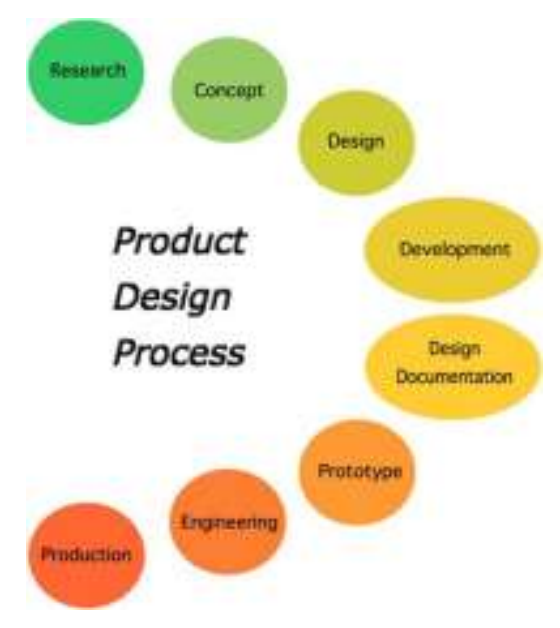

Figure 1 The Product Design Process (sources:Costello Design, 1996)

The below two figures show the AutoCAD 2D engineering drawing of coffee table design with a different missing element in standard 2D drafting for Industrial Design. In figure 2, there is no detailed explanation provided for the extra view welding parts and the hidden line. In figure 3, on the other hand, there is no difference found between the hidden line and the object line. Above all, these missing information adversely influence the result of the students' project.

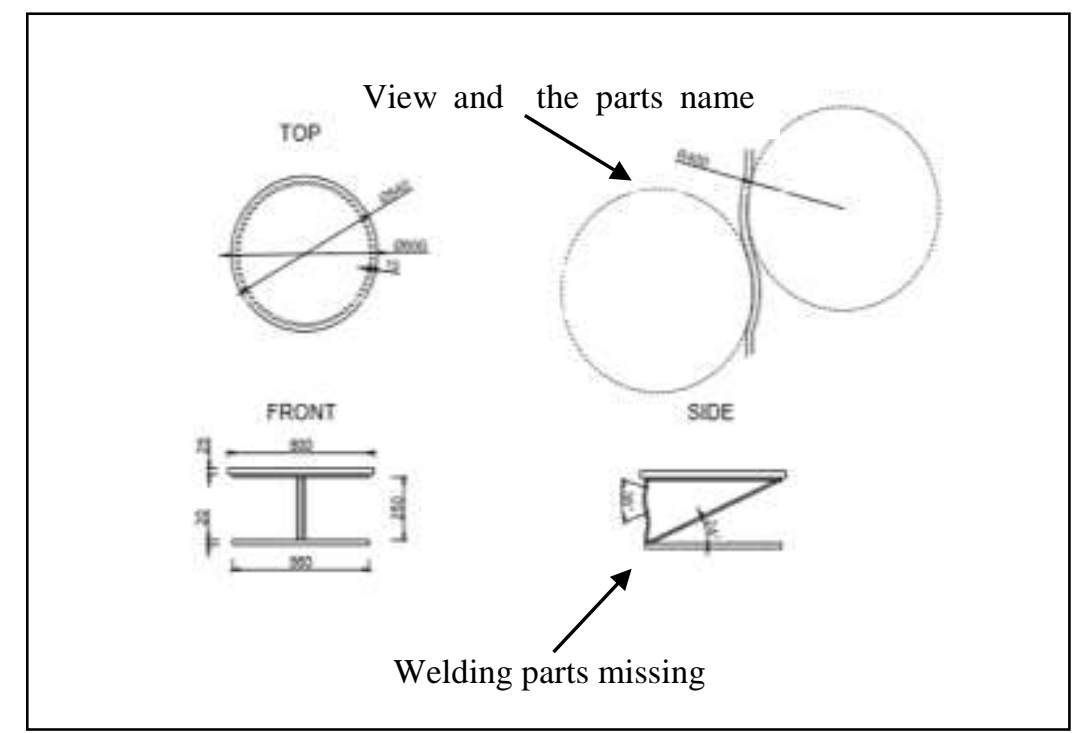

Figure 2: A sample of coffee table design project engineering drawing (Source: BFPD, 2016) 


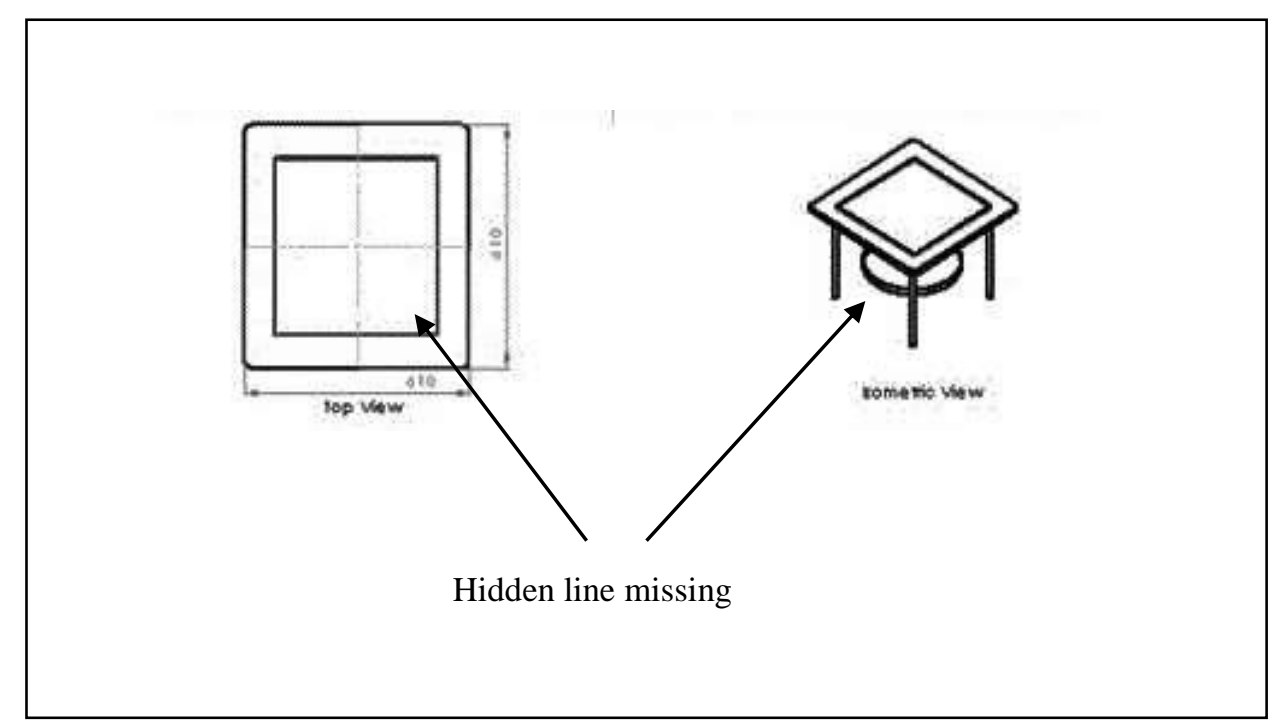

Figure 3: A sample of coffee table design project engineering drawing (Source: BFPD, 2016)

This paper focuses on the student's competency in adopting the AutoCAD 2D drafting. This is due to the fact that some of them do not realize the importance of $2 \mathrm{D}$ engineering drawing usage in their studies. The students are required to be skilful in a visualization method (e.g., 2D engineering drawing) as a reference to prepare a prototyping process (Lothrop, 2012). Diraso et al. (2013) asserted that poor engineering drawing becomes one of the main reasons the graduates had difficulty in getting a jobs in technical drawing fields. This was because they could not intrepret and read the engineering drawing accurately (Abdullah, 2015). In other words, the graduates are unable to meet the basic requirement of the design job .

\section{Methodology}

The sequential explanatory design was applied in this study, which implies collecting and analizing quantitative and then qualitative data in 2 consecutive phases within one study. The objective of choosing this approach was to find out which aspect of AutoCAD 2D engineering drawing that causes the students' poor performance. The data were first collected from the Year 2 and Year 3 students' academic records from AutoCAD assignment and engineering drawing part in Design Project. These students have learned AutoCAD since Year 1. The total sample was 18 students. There were 7 students from Year 3 and 9 students from Year 2. To identify the students' performance of AutoCAD 2D drafting, they were assigned to work on several assessments whereby their results were recorded. These assessments included 4 minor assignments, 1 examination and 1 major final drawing. The final drawing was based on either their own project or a selected product given to them. After that, the students' result for 2D engineering drawing were checked and recorded. Since there were 6 projects in one term, the students were compulsory to produce 6 pieces of $2 \mathrm{D}$ engineering drawings by the end of the term.

The SPSS software was used to get the means score both subjects. SPSS was chosen because of its popularity in academic and sciences social, making it the most widely used packages of its type (Arkkelin, 2014). After the data being analysed, the semi structured interviews were conducted with the students to determine the factors that contributed to poor performance in AutoCAD 2D engineering drawing. The student's weak factors can be detected through the probing question that will be asked in this semi structured interviews (Freeman, 2006) . The Atlas Ti software was used for the interview data analysis. The software will help to analyze the qualitative data, especially the discussion and documentation (Rambaree, 2012). 


\section{Result}

\begin{tabular}{lrrr}
\hline \multicolumn{4}{c}{ Statistics } \\
\hline \multicolumn{1}{c}{ N } & Design Project & AutoCAD \\
& Valid & 18 & 18 \\
& Missing & 0 & 0 \\
Mean & 2.6667 & 3.6667 \\
Std. Deviation & .97014 & 1.23669 \\
Variance & .941 & 1.529 \\
\hline \hline
\end{tabular}

Table 1 Descriptive Statistic Design Project and AutoCAD marks result

Table 1 shows the descriptive statistic for both Design Project and AutoCAD. It was observed that the students in AutoCAD class scored a higher mean of 3.6667 as compared to Design Project 1, with the mean score of 2.6667. This concluded that students performed better in AutoCAD class. In other words, the outcomes of the engineering drawing in AutoCAD class were better than Design Project modules.

\begin{tabular}{cccc}
\multicolumn{3}{c}{ Design Project } \\
\hline \hline Valid & F & Frequency & Percent \\
& D & 5 & 11.1 \\
& C & 9 & 50.0 \\
& B & 1 & 5.6 \\
& A & 1 & 5.6 \\
& Total & 18 & 100.0 \\
\hline \hline
\end{tabular}

Table 2 Percentage scores AutoCAD 2D Engineering Drawing result grade (Design Project module)

Table 2 shows the students' scores ranging from A to $\mathrm{F}$ for $2 \mathrm{D}$ engineering drawing in Design Project modules. Only $5.6 \%$ of the students scored an A and a B in this course. In details, 50\% of the students got a C and $27.8 \%$ of them got a D. Unfortunately, $11.1 \%$ of the students failed their project. The analysis concluded that most students did not perform well in AutoCAD 2D engineering drawing in Design Project.

\begin{tabular}{rrrr}
\multicolumn{4}{c}{ AutoCAD } \\
\hline \hline Valid & F & 1 & 5.6 \\
& Frequency & Percent \\
& D & 2 & 11.1 \\
C & 5 & 27.8 \\
B & 4 & 22.2 \\
A & 6 & 33.3 \\
Total & 18 & 100.0 \\
\hline \hline
\end{tabular}

Table 3 Percentage Scores AutoCAD Module 
Table 3 presents the details of the students' results in AutoCAD module. The analysis showed that $33.3 \%$ of the students scored an $\mathrm{A}$ and $22.2 \%$ of them got a B. In addition, $27.8 \%$ of them got a $\mathrm{C}$ and $11.1 \%$ got a $\mathrm{D}$. However, only $5.6 \%$ failed the module. This concluded that most students did better in AutoCAD modules.

\subsection{Interview approach}

There were 11 students selected to participate the interview because get the low grade AutoCAD 2D engineering drawing in Design Project. All the interviews were conducted face to face. There were 3 main questions and each main question have 2 or 3 sub question which it will give contains information. $\mathrm{P}$ means the participant. P1 to P8 is from Year 2 and P9 to 11 is Year 3 batch. Interview questions and responses are as follows with responses in italics. Question 1 is to explore and identify levels of knowledge of students about the AutoCAD 2D engineering drawing.

Question 1

How would you describe AutoCAD 2D engineering drawing and do you know about the AutoCAD 2D engineering drawing?

P1: I know the dimension. We use it to draw a flat object. It is easy to use, but sometimes it also looks complicated. There are too many functions in the software. The interface is not nice and not user friendly.

P2: The measurement and the dimension of the product. I do not really understand the AutoCAD software. When I used it to draw design project, I faced a problem when drawing a more complicated shape.

P3: The top view, side view, and orthographic drawing, yes, I know about it.I understand the technical drawing. But sometimes I curious on measurement and AutoCAD menu.

P4: All measurements must be correct and it is related to skill drawing. AutoCAD is a platform to make a technical drawing. It can be used to draw $2 D$ as well.

P5:Oh.. I learn before, but now I forget.I'm still not remember the menu of the software.Form my opinion, those who has strength in mathematics or measurement, it's very easy to apply AutoCAD 2D.

P6: It has 2D measurement. I think AutoCAD can be used to prepare a technical drawing, but I am not professional. It is too difficult for me. I'm very weak on calculation or mathematics

P7: It is a software to draw a more detailed in 2D engineering drawing.

P8: Yes, I know it is a 2D drawing software that shows the dimensions.

P9: Yes, sometimes the subject is boring and the software is also boring. The interface is difficult.

P10: Yes, I know. It can provide detailed dimensions, but it is very complicated and need to play keyboard,and remember the command.

P11: Yes, I know. It is a software. I guess. It is not really a good software. It is hard to use.

Most participants complained about the AutoCAD 2D was difficult to use. Some students mentioned that the interface design was boring and too many menus in AutoCAD. However, many of them agreed that the AutoCAD was adopted to do a detailed 2D engineering drawing. They also knew about orthographic drawing. Moreover, some participants mentioned about basic knowledge of mathematics and measurement need to be 
applied in AutoCAD. They also feel difficult to draw complicated design such like organic shapes. To sum up, the majority of the students pointed out that the software is difficult to apply in their own design. This problem might imply that they lacked a technical thinking skill in the software application. Therefore, Question 2 is to determine the factors influencing students' difficulty in AutoCAD 2 engineering drawings.

Question 2

Why and what do you feel difficult about the AutoCAD 2D engineering drawing? Is it because of the interface design, lecturer, timetable, lecture notes, assignments or lab facility or anything that I'm not mentioning here?

P1: Actually the software is fine. The problem is I always come late for the class, so it is my own disciplinary problem. I missed the early lecture. My lecturer, computer lab and the timetable of the class are fine for me.

P2: It is quite okay. It is not totally $100 \%$ difficult to use. The timetable is fine. Even if I could not remember to apply AutoCAD in the class, the lecturer helped and guided me. The computer lab was complete.

P3: I think everything is okay. When doing project I, I have forgotten about it already so I used traditional technical drawing. I am not practicing AutoCAD after the class.

P4: For lecture, we come late for the class so it is our problem. Others are okay. The lecturer helps us a lot, but it is difficult because we miss an earlier lecture. This is our problem. I also do not practice after the class.

P5: It is a complicated software as compared with other softwares to transform from $3 D$ to $2 D$. The AutoCAD starts with $2 D$. Time is not enough. AutoCAD is difficult. I need more time to learn. I only remember in the class because it is easy to understand, but when I go home, I forget how to use it. The lecture is fine and easier to understand. Lab facility and class timetable are fine for me. Too many interfaces to remember.

P6: It is okay so far, but I need guidance to apply AutoCAD. I am very weak in computer technology. I can follow the instruction in the class. If I do not know, I will ask. The lecturer helps me and lecture notes are also fine for me.

P7: So far there is no problem from my side. The PCs (computers) are enough, and the timetable is also appropriate. The lecture is also okay, no problem. It is easy to understand. The lecturer gives us suitable notes, exercises and assignments.

P8: For facility, it is okay. But learning once a week is not enough for me. Therefore, I forgot. That is why I am weak in this software. AutoCAD is more suitable to engineers, it is more technical.

P9: There is no problem in class. All is fine for me. The lecturer teaches us all fundamental of AutoCAD but I do not have enough time to learn and practice it. Sometime, we are busy with other activities.

P10: There was no problem in class facility and lecturer. All is fine for me. Lecturer teaches us all basic about AutoCAD and also the engineering drawing, but I always forget how to apply. It is very complicated and need to know how to play keyboard and remember the command.

P11: The class runs well actually and the lecturer does not give any problem to me. Sometimes, the lecturer helps and guides me how to draw. The computer lab is also good enough.

One of the main problems faced by most students was they forgot how to apply AutoCAD 2D. They could not remember the command and the menu in AutoCAD because they did not practice quite often after the class. 
They could only understand what the lecturer had delivered in the AutoCAD class. Some of them attended the AutoCAD class late, and therefore they had missed a lot of important information. There was no complaint about the university's lecturer and computer lab facilities. They could understand the lectures as well. The assignments given to the students were also suitable for their level. Most importantly, students had to practice the software at home or with their friends to remember the software application, so they could apply it for their own design. Unfortunately, the students always expected from their lecturer to assist them without having a willingness to learn. One conclusion can be drawn was the learning attitudes of the students become an obstacle for them in their studies. The next question is related to the practice of AutoCAD 2D in the design project module. It is relevant to their spatial skill and technical thinking.

Question 3

How frequent you apply AutoCAD 2D engineering drawing in the Design Project module? Why you do better in AutoCAD class, but not in Design Project? Is it because of your design is complicated to draw? How about the Design Project lecturer?

P1: Sometimes it depends on my design, but my design project is not really difficult to draw. In AutoCAD class, it is a more practical tool. The project design will involve everything. It is more independent. The lecturer helps and guides us, but the problem is we need think how to solve our problems.

P2: I rarely practiced. I need time to think how to draw using AutoCAD. That is why I prefer the traditional way. Sometime I just guess the dimension in my drawing. The assignment given in AutoCAD itself is easy. The lecturer helps and guides us, but I forget when going back home.

P3: Sometimes. But I forget how to draw some drawings that involved tangent. Anyway, we have hand sketches into $3 D$ already. In terms of 2D, I do not know what measurement value is needed to start my design. The drawing in AutoCAD class is easy because the lecturer guides us. It is different from Design Project. We need to solve the drawing problem by ourselves. So far the lecturer helps but we need to solve it by ourselves.

P4: I rarely use it. It is complicated, but I try my best to apply it. I apply manual technical drawing and the traditional way. Anyway Design Project is about the design process and it is given individually to us to solve the problem. There is no problem with the lecturer because I understand that this module requires a certain level of independence.

P5: Sometimes I apply also. I submit my AutoCAD final assignment with the same drawing in my Design Project. Therefore, no problem at all. The lecturer guides us. I think the problems are time management and procrastination.

P6: For the first and second project, I apply traditional style. When doing the next project, I apply it. The problem is it is difficult to transfer our 3D hand sketches to 2D. I do not know how to measure the curve, tangent and radius part measurement. I also forgot the calculation part. I am weak in technical parts as well. The lecturer guides us, but I forget because I do not practice it in depth.

P7: I rarely apply. It is a good software that can be used to convert our drawing directly from $3 D$ to $2 D$. It is not time-consuming. Since we were Year 1 students that time, we did not learn any advanced software. We learnt the basic only. The lecturer helps and gives a lot of opinions about my design. The technical part must be solved by myself. 
P8: I rarely apply it because it is complicated. I do not have enough time to think, learn and explore. I prefer hand sketches. It is my weakness. I do not like calculation and technical parts. I am weak in $2 D$ engineering drawing for Design Project because I cannot solve the technical drawing itself.

P10: I only applied it when I was Year 1. In Year 2 and 3, I had other software modules. Therefore, there was no problem at all. But for me, AutoCAD is multitasking. $2 D$ CAD can be used to draw anything such as furniture, product and interior in $2 D$ version. When I was Year 1, it was still new for me, I could not think any technical parts and understand well about $2 D$ engineering drawing.

P11: Sometimes I apply. I apply traditional technical drawing because I forget how to use AutoCAD. Engineering drawing is quite difficult for me. I prefer hand sketches or hand drawing because I do not need to think the technical parts.

The above responses captured that most students rarely applied AutoCAD 2D engineering drawing in their design project modules. This was because they were unable to think about the technical parts in their design. They also experienced some problems with their own design. They were weak in technical thinking as well. They were also not interested in reading the manual of 2D engineering drawing. Overall, the conclusion was the students would prefer to adopt the easiest way to complete their design instead of investing time to learn the AutoCAD software because due to a lack of technical skills AutoCAD 2D engineering drawing.

\section{Conclusion and recommendation}

Based on the above discussion, the students' academic performance of AutoCAD 2D engineering drawing was not necessarily affected by the software. In fact, it's highly depended upon the students' technical thinking skill. The main reason was the students did not practice the software routinely due to their inadequate level of understanding of 2D engineering drawing and technical parts. Particularly, the software is also difficult to apply. Thus, it affected their attitude indirectly and they chose to go for the easiest way. According to the findings of the present study, the following recommendations were made to help students enhance their performance in AutoCAD 2D engineering.

1. The faculty and departmental libraries should be equipped with textbooks with the latest edition about 2D engineering drawing and AutoCAD to encourage students to cultivate a good reading culture .

2. Design interesting and easy modules for BFPD students to understand the courses better.

3. Enhance AutoCAD 2D engineering drawing to develop the students skill.

4. Lecturers should give extra tutorials to improve the student's understanding of the AutoCAD 2D engineering drawing.

5. Students should achieve full attendance at AutoCAD class with good performance.

6. BFPD's students should spend more time on their engineering drawing to meet their own expectation of the course.

7. The faculty should send the lecturers for AutoCAD and Engineering Drawing training to improve their teaching method.

8. Design a multimedia or application specialist for BFPD 2D AutoCAD engineering drawing references. 


\section{Acknowledgement}

The Authors appreciate the participation from students of the BFPD, First City University College and the University to make this project a complete one.

\section{References}

Abdullah, Z. (2015). Improving Malaysian engineering graduate ability to read and interpret engineering drawings. UTEM.

Arkkelin, D. (2014). Using SPSS to Understand Research and Data Analysis. Psychology Curricular Materialssychology Curricular Materials, 194.

Awang, D. bin. (2000). Rekabentuk Industri Dalam Kejuruteraan Mekanikal.

Beckmann, G., \& Krause, D. (2010). Improving the mechanical design education by hands-on experience with machine parts. In DS 62: Proceedings of E and PDE 2010, the 12th International Conference on Engineering and Product Design Education - When Design Education and Design Research Meet.

Eteli, I., \& Eniekenemi, E. (2016). Effect of Autocad Software In Teaching Isometric And Oblique Drawing Among Female Students In Federal Science Technical College Tungbo, Bayelsa State. International Journal of Education and Evaluation ISSN, 2(2), 2489-73.

Freeman, T. (2006). "Best practice" in focus group research: Making sense of different views. Journal of Advanced Nursing, 56(5), 491-497. https://doi.org/10.1111/j.13652648.2006.04043.x

Kennedy, L. (2014). A Brief History of AutoCAD. Retrieved from http://www.scan2cad.com/autocad-brief-history/

Lothrop, T. (2012). Design Drawing - An Integrated Visualization System. The Ohio State University.

Nichols, B. (2013). Valuing the Art of Industrial Design. Washington, D.C.

Rambaree, K. (2012). Three Methods Of Qualitative Data Analysis Using ATLAS . ti : " A Posse Ad Esse ." ATLAS.ti User Conference 2013, 1-15. https://doi.org/http://dx.doi.org/10.14279/depositonce-4840

Reddy, K. V. (2008). Textbook of Engineering Drawing 2nd Edition. BS Publication. Hyderabad. Retrieved from http://books.google.com.my/books?id=AfNV215sPAC\&lpg=PA1\&pg=PA20\#v=onepage \&q\&f=false

Seats, C. A. D. (2015). AutoCAD Alternatives Are Alive and Well in Product Design Graebert: Millions of 2D CAD Seats. Retrieved from http://www.digitaleng.news/de/autocadalternatives-are-alive-and-well-in-product-design/

Serdar, T. (2015). Enhancing Spatial Visualization Skills in Engineering Drawing Course. In 122nd ASEE Annual Conference \& Exposition (p. 26.663.1-26.663.12). 